Article

\title{
2D Versus 3D: The Relevance of the Mode of Presentation for the Economic Valuation of an Alpine Landscape
}

\author{
Michael Getzner ${ }^{1, *}$, Barbara Färber ${ }^{1}$ and Claudia Yamu ${ }^{2}$ \\ 1 Department of Spatial Planning, Vienna University of Technology, Vienna 20140, Austria; b.faerber@gmx.at \\ 2 Department of Planning and Environnent, University of Groningen, Groningen 9700, The Netherlands; \\ claudia.yamu@rug.nl \\ * Correspondence: michael.getzner@tuwien.ac.at; Tel.: +43-1-58801-280320
}

Academic Editor: Victor T. King

Received: 13 May 2016; Accepted: 20 June 2016; Published: 22 June 2016

\begin{abstract}
In order to value the transformation of landscapes from an economic perspective, survey respondents are usually presented with pictures of various landscapes with the aim to visualize differences in their appearance. The current paper presents a classroom experiment ascertaining differences, and potential advantages and disadvantages, of $2 \mathrm{D}$ versus $3 \mathrm{D}$ (stereoscopic) presentations of landscape changes. The landscape to be valued was a traditional Alpine pasture in the Austrian Alps as a prominent example of natural and cultural heritage (traditional economy and specific ecology). Two alternative scenarios included, on the one hand, changes in agricultural uses, leading to natural afforestation (reforestation) and decay of existing infrastructure (e.g., hiking trails). On the other hand, significantly extended tourism infrastructure (e.g., new attractions for visitors) was presented. Two groups were presented manipulated pictures (2D/non-stereoscopic), and 3D (stereoscopic) presentations with 3D glasses, respectively. Both groups were then asked for their perception of landscape changes. It turns out that significant differences between the two groups could be detected in terms of the frequency of vacations at Alpine pastures. For instance, respondents in the 3D stereoscopic group stated a significantly higher frequency of trips. However, on the other hand, they did not state a significantly different willingness-to-pay to prevent landscape changes disadvantageous in terms of sustainability. The study results thus suggest that the mode of presentation may affect the valuation of landscape changes depending on the valuation instrument.
\end{abstract}

Keywords: Alpine landscape; valuation of natural and cultural heritage; travel behavior; revealed/stated preferences; $3 \mathrm{D}$ vs. 2D (stereoscopic vs. non-stereoscopic) modes of presentation

\section{Introduction}

While remnants of pristine or wilderness areas can still be found in the Austrian Alps, the landscape has been transformed over centuries by human cultivation (agriculture, forestry). This is especially important for Alpine pastures, which have led to a specific appearance of the landscape, as well as to a rich diversity of animal and plant species that are native to these pastures and which would not exist if human cultivation had left the original land cover of forests intact. The current appearance of the landscape provides the basis for Alpine tourism-a major sector of the Austrian economy. Alpine pastures and a diverse landscape form the typical and highly esteemed images and metaphors of intact ecosystems and sustainable agriculture and forestry, and thus can be considered an important element of the natural and cultural heritage in Alpine regions. They also form an essential part of the perceived beauty of Alpine landscapes; tourism marketing and tourist guides market the original pasture landscape as an essential element of enjoying a relaxed, natural environment. While 
hiking and other Alpine activities mainly take place during summer, pastures also provide the slopes for skiing during the winter season. However, it is less important for the tourism industries whether Alpine pastures as a key element of the landscapes in the Alps are natural from an ecological point of view. Images and metaphors transported by marketing agencies and tourism destination management seem to be more important in this context (cf. [1,2]).

Tourism itself may have significant negative effects on Alpine pastures in terms of ecological degradation and overcrowding, but the structural change in agricultural production has led to the abandonment of marginal pastures by reducing the intensity of cultivation. Re-forestation and the loss of biodiversity typical to pastures may therefore also lead to a changing appearance of the Alpine landscape (cf. $[3,4])$. The positive external effects of high-Alpine agriculture, e.g., grazing cattle and sheep, still are a major argument in favor of subsidies for high-Alpine farmers in order to preserve the cultural and natural heritage of traditional pastures.

While the importance of the Alpine landscape per se is undoubtedly high, the economic value of recreation at Alpine pastures for visitors (domestic and international tourists) is still an open question. From a methodological viewpoint, landscape changes due to different agricultural practices may be valued by a wide range of economic valuation methods; one might ask for the tourists' (or residents') willingness-to-pay for different scenarios of conservation of the Alpine landscape, or for the revealed and stated frequency of vacations in the Alpine tourism areas depending, among other factors, on different developments of the landscape [2]. However, the practical implementation of economic valuation methods is often limited to presenting respondents with several scenarios described verbally and by means of pictures of different Alpine landscapes. In some studies (e.g., [5,6]), a picture is manipulated to show different stages of development. Nowadays, new techniques are available to present respondents with such developments, for instance, stereoscopic (3D) presentations. 3D models and their presentation are regularly used in urban and regional planning for presenting different scenarios of urban developments to stakeholders, but less for valuing landscape scenarios. By now, it is unclear how a different presentation of a certain development of the appearance of a landscape might alter the respondents' perception and, subsequently, their valuation of landscape changes. In addition, the perception and appeal of a certain landscape, of course, also depends on a diverse range of landscape elements such as the included details, the composition of the ecosystem, species, and also the angles of the presentation itself.

Against this background, the aim of this paper is to shed more light on the differences of the individual valuation of changes of an Alpine landscape characterized by pastures as important elements of cultural and natural heritage owing to two- (2D) versus three-dimensional (stereoscopic 3D) presentations by presenting one specific landscape by different presentation means (2D vs. 3D). In particular, the purpose of this paper is to find answers to the following questions:

- How are changes of a typical Alpine landscape (pasture) valued by respondents in an experimental setting?

- Are the revealed (actual) and stated (potential, hypothetical) travel frequencies different between scenarios?

- How does the form of presentation (3D vs. 2D) influence the respondents' answers?

- How do respondents perceive advantages or disadvantages of 3D vs. 2D presentations?

The structure of the paper is as follows: In Section 2, there is a brief overview of literature on presenting environmental, regional and urban development by means of different presentation media. In Section 3, the experimental setting is presented, and the main hypotheses are developed. In Section 4.1, the descriptive results of the study are discussed, and in Section 4.2 the econometric results with respect to the determinants of the respondents' willingness-to-pay and their revealed and stated travel frequency are presented. Finally, in Section 5, the results are summarized, and conclusions are drawn. 


\section{Valuing Landscapes by Visual Presentations}

Valuing landscape changes and transformations from an economic or social science perspective is usually made by presenting different management scenarios to survey respondents or tourists. Very often, changes of landscapes are visualized through manipulating pictures and presenting these. On the one hand, valuation may be approached by assessing the recreation value of the current appearance of the landscape (e.g., by modeling trip frequency determined by travel cost and environmental and socio-economic attributes) in combination with hypothetical scenarios. This combination of revealed and stated preference techniques has been made fruitful by a number of scholars (e.g., $[7,8]$ ). On the other hand, willingness-to-pay (WTP) to prevent deterioration or to enhance the quality of landscapes has widely been ascertained by means of visual representations (e.g., $[5,6])$.

In spatial planning, new techniques have now been developed in order to visualize urban or rural landscapes more realistically, including the modelling of city landscapes with respect to urban development or urban sprawl. Spatial planning techniques include, of course, maps and plans, but also different forms of visualization (cf. $[9,10])$. Visualization modeling has the aim to create an accurate context for development proposals and to explore possible future development scenarios. Visualizations are commonly used to overcome the lack of communication between different parties as they can translate conventional drawings and analyses into a format that may be more comprehensible [11]. The lack of mutual communication can lead to inconsistencies in the planning and design process. Thus, 3D visualization often works as a communication tool for a decision-making process [12].

In the context of environmental valuation, Fiore et al. [13] present the benefits of virtual experiments in a laboratory. They conclude that values elicited in virtual settings may reflect the respondents' beliefs more closely with reference to the "true beliefs" compared to a standard survey situation, owing to the more realistic perception of respondents [14].

While environmental valuation techniques have only recently included experimental settings, urban and regional planning has used 3D simulations regularly. For instance, Grêt-Regamey et al. [15] present an interactive simulation of city developments at Masdar City to present and highlight ecosystem services trade-offs with the aim to develop innovative sustainable urban strategies. Another application of 3D modelling for urban policies was published by [16] who present applications of the "three dimensional city" for transport planning and mobility decisions. In energy policy, virtual experiments and simulations have been used, e.g., for siting wind power plants [17].

Using digital visualization, two kinds of displays can be used: (Auto-) Stereoscopic (3D) and non-stereoscopic (2D). Ref. [18] point out that the applications of 3D scenes are numerous as they range from entertainment (video, games) to more specialized applications such as educational or medical applications. The stereoscopic display increases visual authenticity due to the simulation of depth, based on the human brain and eye physiology (stereopsis). Stereoscopic images are using systems to display stereo images presenting two slightly different images to the right and left eye. Tauer [19] (p. 144) points out that the stereoscopic display only produces a 3D effect due to two distinctive flat depth levels. The main advantage lies in the easy encoding of the images [19]. In contrast, a disadvantage is that owing to a fixed focal length of a stereoscopic display, e.g., the screen, results can conflict within our visual system. Viewing stereoscopic images may thus have negative short-term consequences, including difficulty fusing binocular images and therefore reduced binocular performance (e.g., [20]).

For viewing stereoscopic pictures, two systems are at stake, i.e., stereoscopic displays with glasses in contrast to autostereoscopic displays where no glasses are needed. The most cost-effective technique for stereoscopic display is the use of anaglyphic lenses as viewing glasses to achieve the 3D effect. Different colored filters encode each eye's image. Thus, typically anaglyph images contain two different complimentary colored images. Because of the colored filters in the glasses, one colored image is only destined for one eye and the image is locked for the other one. This creates the 3D effect. The 
cost-effectiveness is juxtaposed by the disadvantage of color renderings as both images and the glasses are colored and thus can influence the quality of the image.

\section{The Experimental Setting and Testable Hypotheses}

\subsection{The Classroom Experiment}

In order to answer the research questions of the current study, 85 spatial planning students at the undergraduate level (mainly of Austrian origin) were recruited for the classroom experiment [21]. As an incentive to participate, students could earn points for the upcoming economics exam. As the sample of participants of the experiment is not representative, we do not expect reliable economic values in absolute terms (e.g., consumer surplus or willingness-to-pay in EUR). However, in order to test the hypotheses formulated below, we reasonably assume that the effect of the different modes of presentation (2D or 3D) alters economic values in the same direction, i.e., qualitatively similar to the whole population. The use of classroom experiments in general is a widely used and accepted approach in psychological, social and economic sciences-for instance, in behavioral economics (cf. [22]).

For producing the stereoscopic images for our classroom experiment, we faced the challenges described above in Section 2. According to the size of the spatial simulation laboratory, the position of participants and the size of the screen we identified a stereoscopic optimum with a distance of intersection for two images of $2.5 \mathrm{~cm}$. We used the software "Free 3D Photo Maker" (Digital Wave Ltd., London, UK) in order to produce the (stereoscopic) 3D images on the basis of the 2D pictures of an Alpine pasture.

Students registered for the experiment during certain time slots and were then randomly assigned to a group (treatment); in order to guarantee equal conditions of the experiment, we limited each group size to 15 respondents, which is the maximum capacity of the spatial simulation laboratory. Prior to the experiment, students did not know whether they would be presented 2D or 3D images.

The spatial simulation laboratory at Vienna University of Technology is equipped with a 3D virtual reality (VR) environment including a 3D stereoscopic rear projector, tractors and pointers; the resolution of the images both in the 2D and the 3D group were equal (for further information on the laboratory, see [23]).

Students of the 2D group were verbally introduced to the survey in a standard seminar room (see Figure 1), and then handed the self-administered questionnaire; the 2D image and the two development scenarios (see Figure 2) presented below were shown by means of an overhead projection. In total, 43 students were assigned to the 2D groups (and 42 to the 3D treatment, respectively).
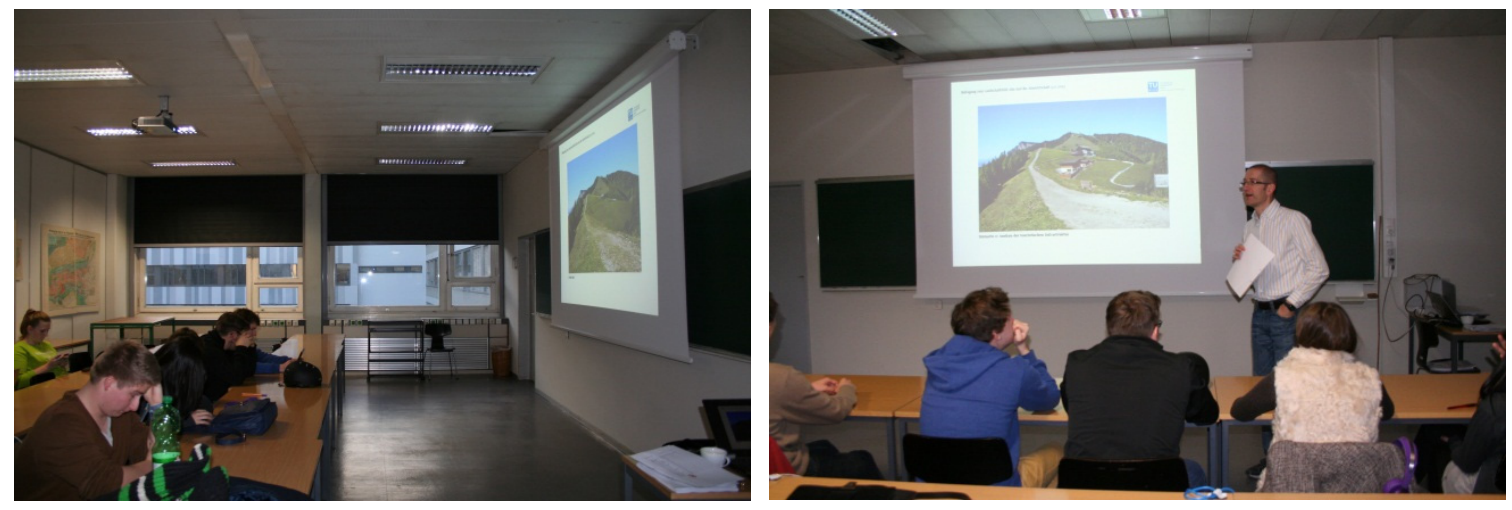

(a)

Figure 1. Cont. 

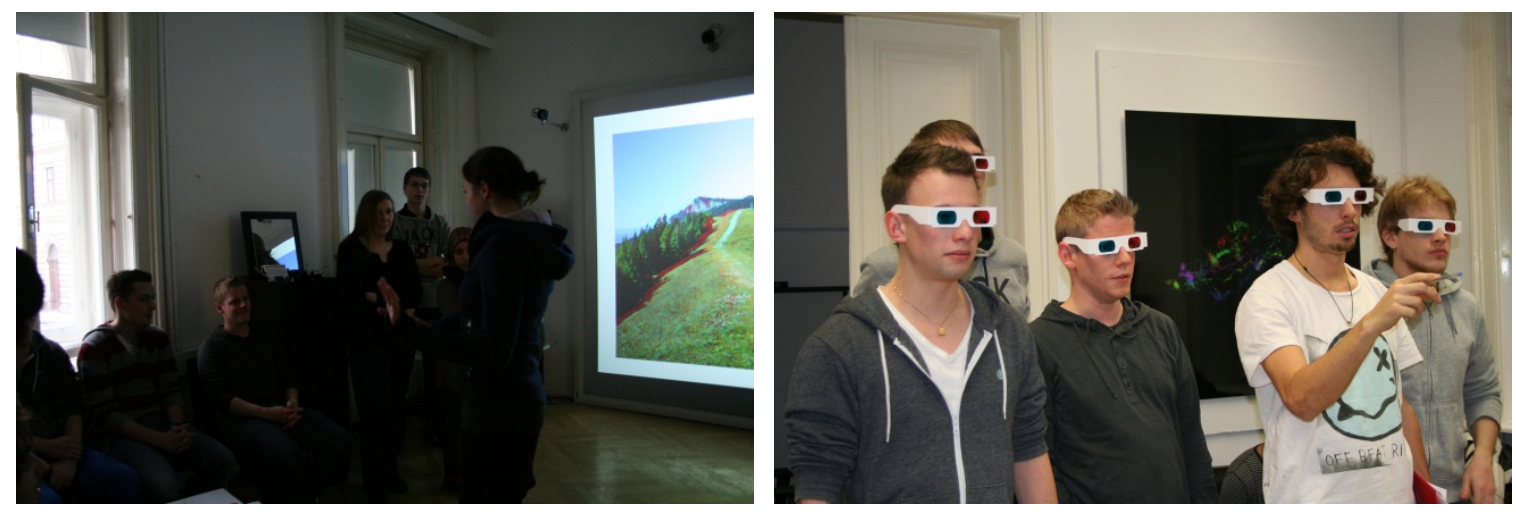

(b)

Figure 1. The classroom experiment: 2D seminar room (a); and 3D presentation in the spatial simulation lab (b) of the Vienna University of Technology (source: own pictures).

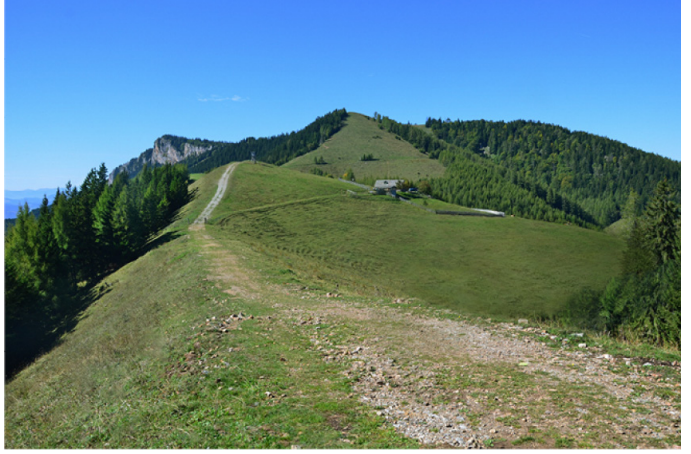

(a)

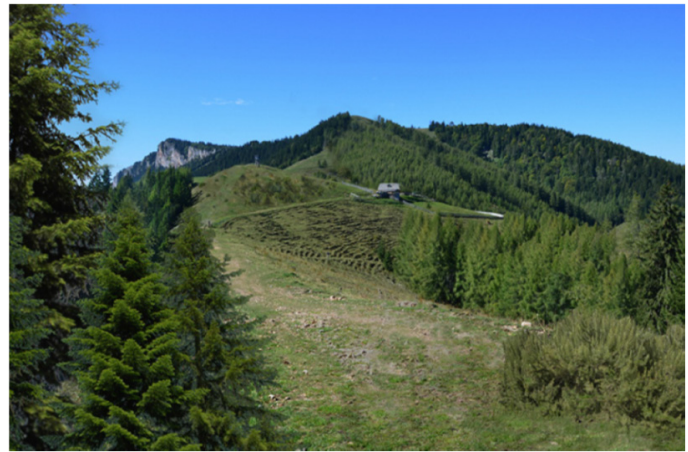

(b)

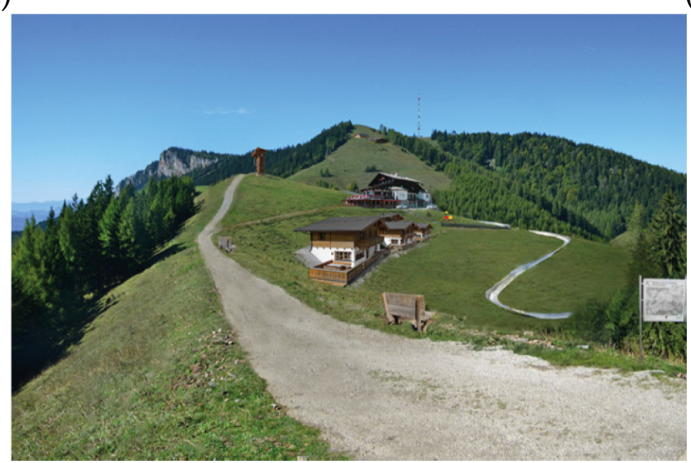

(c)

Figure 2. Alpine landscape: status quo of pastures (a) and possible future scenarios ("Afforestation" (b), “Tourism” (c)) (source: own pictures).

In the spatial simulation lab, the verbal introduction and the whole experiment were completely equal to the 2D treatment, but students were in addition handed 3D glasses in order to watch the images of the original landscape and the two potential development scenarios. Figure 1 presents impressions from both the classroom (seminar room) and the simulation laboratory. Students then filled in the self-administered questionnaire after watching the $2 \mathrm{D}$ or $3 \mathrm{D}$ pictures. 


\subsection{Development Scenarios of Alpine Pastures and Testable Hypotheses}

As mentioned before, we presented respondents three pictures; the original one displayed an Alpine pasture which proved to mirror the usual image, e.g., in tourism brochures, of a typical Alpine pasture. Due to space restrictions, we cannot describe the procedure to test for similarities between pictures in detail. In a nutshell, we took several pictures of tourism brochures, analyzed them with respect to their contents (forests, open spaces, Alpine pastures, meadows, and blue sky) by breaking up the pictures in a $1 \mathrm{~mm} \times 1 \mathrm{~mm}$ grid, and then took our own picture in high resolution in order to have a picture available that could be manipulated [21].

Based on this picture, two scenarios were implemented by manipulating the original picture and adding (or removing) several components of landscape changes such as trees, hard-surfaced paths and roads, and tourism infrastructure-all jeopardizing the appearance of a typical Alpine pasture as a part of natural and cultural heritage. Scenario 1 mirrors a development that might reduce biodiversity of Alpine pastures, and change the landscape from the image of a landscape attractive for tourists to an area largely afforested owing to reducing or abandoning the traditional way of managing Alpine pastures (scenario "Afforestation"). Scenario 2 also assumes a drastic change in the management of the pasture and intensively develops tourism infrastructure in terms of an Alpine hut upgraded to a restaurant, with information panels, and other sports and leisure infrastructure (scenario "Tourism"). The landscape elements added to the original picture all represent probable and realistic elements of landscape changes according to the two scenarios.

After having manipulated the original 2D picture to display the two potential scenarios, we then produced the corresponding 3D pictures. Figure 2 presents the original picture, and the two manipulated pictures displaying the scenarios 1 and 2.

In order to test for differences in the perception, and consequently, in the economic valuation of the two scenarios, we structured our questionnaire as follows. First, a block of questions ascertained preferences of respondents and the frequency of vacations in Alpine landscapes, including several dimensions to describe an Alpine pasture. Second, the status quo of the appearance of the landscape, and the two scenarios, were valued by respondents, including their hypothetical frequency of vacations if one of the two scenarios were to be become reality. Third, respondents could state their willingness-to-pay for a landscape conservation funds to manage and maintain Alpine pastures, and, alternatively, to avoid scenario 1 or 2 . Fourth, the questionnaire included statements regarding the $2 \mathrm{D}$ and the $3 \mathrm{D}$ presentation, respectively. The $2 \mathrm{D}$ group was asked about their opinions about a potential 3D presentation, e.g., whether they would expect more information if they would have had a 3D presentation instead. The 3D group was asked whether they thought that $2 \mathrm{D}$ pictures were enough for perceiving landscape changes. Both groups were also asked whether they thought that 3D could provide more information, or an improved spatial perception than 2D pictures. Finally, some socio-economic questions (e.g., income) were asked.

Our main six hypotheses to be tested are (for a list of variables, see Table 1):

1. $\mathrm{H}_{1}$ : Travelfrequency $2 \mathrm{D}$,Status quo $\neq$ Travelfrequency $_{3 \mathrm{D}, \text { Status quo }}$

2. $\mathrm{H}_{2}$ : Travelfrequency $2 \mathrm{D}$, ,Scenario $1 \neq$ Travelfrequency3D,Scenario1

3. $\mathrm{H}_{3}$ : Travelfrequency $2 \mathrm{D}$, Scenario2 $\neq$ Travelfrequency $3 \mathrm{D}$,Scenario2

4. $\mathrm{H}_{4}: \mathrm{WTP}_{2 \mathrm{D}, \text { Scenario } 1} \neq \mathrm{WTP}_{3 \mathrm{D}, \text { Scenario } 1}$

5. $\mathrm{H}_{5}: \mathrm{WTP}_{2 \mathrm{D}, \text { Scenario2 }} \neq \mathrm{WTP}_{3 \mathrm{D}, \text { Scenario2 }}$

6. $\mathrm{H}_{6}: \mathrm{WTP}_{\varnothing(2 \mathrm{D}, 3 \mathrm{D}), \text { Scenario1 }} \neq \mathrm{WTP} \varnothing(2 \mathrm{D}, 3 \mathrm{D})$, Scenario2 
Table 1. Variables of the empirical estimations.

\begin{tabular}{|c|c|}
\hline Variable Name & Description \\
\hline \multicolumn{2}{|l|}{ Dependent variables: } \\
\hline Travelfrequency & $\begin{array}{l}\text { Frequency of vacations (trips) at an } \\
\text { Alpine pasture landscape }\end{array}$ \\
\hline WTP & $\begin{array}{l}\text { Willingness-to-pay (WTP) of respondents to } \\
\text { prevent either scenario } 1 \text { or scenario } 2 \text { (EUR) }\end{array}$ \\
\hline \multicolumn{2}{|l|}{ Explanatory variables: } \\
\hline \multicolumn{2}{|l|}{$\mathrm{T}_{\mathrm{i}}$} \\
\hline Travelcost & $\begin{array}{l}\text { Travel costs of respondents for their visits to an } \\
\text { Alpine pasture landscape (EUR) }\end{array}$ \\
\hline \multicolumn{2}{|l|}{$\mathrm{G}_{\mathrm{i}}$} \\
\hline Scen1 & $=1$ for scenario 1 \\
\hline Scen2 & $=1$ for scenario 2 \\
\hline Group & $=1$ for the sub-sample of the $3 \mathrm{D}$ treatment \\
\hline \multicolumn{2}{|l|}{$\mathrm{S}_{\mathrm{i}}$} \\
\hline Income1 & $\begin{array}{l}\text { Income of respondent (net monthly income, per } \\
\text { person, EUR, natural log) }\end{array}$ \\
\hline Income2 & $\begin{array}{l}=1 \text { for respondents with a income higher than } \\
\text { EUR } 450 \text { (per month, net of taxes) }\end{array}$ \\
\hline \multicolumn{2}{|l|}{$\mathrm{P}_{\mathrm{i}}$} \\
\hline Essential & $\begin{array}{l}=1 \text { for the respondent's view that Alpine pastures are } \\
\text { essential for the landscape }\end{array}$ \\
\hline Identity & $\begin{array}{l}=1 \text { for respondents agreeing to the statement that } \\
\text { Alpine pasture promote the national identity }\end{array}$ \\
\hline Recreation & $\begin{array}{l}=1 \text { for recreation considered to an important } \\
\text { ecosystem service of Alpine pastures }\end{array}$ \\
\hline Experience1 & $\begin{array}{l}=1 \text { for respondents who have experienced the } \\
\text { reforestation of Alpine pastures }\end{array}$ \\
\hline Experience2 & $\begin{array}{l}=1 \text { for the respondent's past experience with intensive } \\
\text { touristic development on Alpine pastures }\end{array}$ \\
\hline
\end{tabular}

The first group of hypotheses tests whether travel frequency is different between the two groups (2D vs. 3D), depending on the scenario presented. The second group tests for differences of willingness-to-pay (WTP) with respect to the form of presentation, as well as the scenarios. As this paper answers the research questions and tests for the hypotheses in an exploratory approach, we do not have a priori assumptions about the direction of each test. For instance, if 3D presentation contain more information and offer a more comprehensive spatial perception of landscape changes, respondents may state a higher travel frequency and a higher WTP in the 3D group, as several studies showed that an increased level of information may also lead to a higher willingness-to-pay (e.g., [24-27]).

Besides analyzing descriptive evidence regarding potential differences according to the hypotheses outlined above, this paper specifically tests the hypotheses by means of two equations which are estimated econometrically:

$$
\begin{gathered}
\text { Travelfrequency } y_{i}=f\left(T_{i}, G_{i}, S_{i}, P_{i}\right), \\
W P_{i}=f\left(G_{i}, S_{i}, P_{i}\right) .
\end{gathered}
$$


Equation (1) outlines the empirical model in order to estimate a "demand function" for vacations in Alpine areas, specifically with the focus on Alpine pastures, on the basis of a travel cost model (cf., e.g., [28]). The frequency of vacations in Alpine landscapes, denoted by the variable "Travelfrequency", should thus be dependent on $T_{i}$ (travel cost) consisting of both conservative estimates of transportation and travel time costs. As we do not aim to provide a representative study, nor measure recreation benefits in absolute terms, neither the choice of costs of travel time nor transportation costs influences the ordinal ranking with respect to scenarios or groups of respondents ([29]).

$\mathrm{G}_{\mathrm{i}}$ contains a vector of grouping variables denoting the scenarios 1 and 2, and differentiating the sample of respondents between the $2 \mathrm{D}$ versus $3 \mathrm{D}$ presentations.

$\mathrm{S}_{\mathrm{i}}$ denotes the income of respondent $i$ which can be reasoned by the standard assumption that travel frequency as a normal consumer good, as well willingness-to-pay for landscape conservation, is positively correlated with individual (or household) income. Other socioeconomic characteristics that usually determine economic values such as age, and education, are not included since our (non-representative) sample of participants in the experiment is too homogenous for testing the influence of these variables in the econometric estimations presented below.

$P_{i}$ forms a vector of variables comprising the strength of agreement to a number of statements, e.g., regarding the role of Alpine pastures for Alpine landscapes as part of cultural and natural heritage, and the experience of respondents with developments at Alpine pastures potentially considered unfavorable (e.g., afforestation, intensive tourism development). The questionnaire also included an elicitation of activities during the vacations in the Alps. As Alpine pastures are mainly used by hikers during the summer season, the statistical analysis also does not account for these rather homogenous activities as explanatory variables in the estimations.

With respect to equation (2) presented above, we basically assume comparable influences of the variables, and include all variables in our willingness-to-pay (WTP) function except for travel costs (see Sections 4.1 and 4.2 below).

\section{Empirical Results}

\subsection{Descriptive Survey Results}

Owing to restriction of space, only selected descriptive results will be presented in this paper (the entire questionnaire and further descriptions of the experiment, all the data and empirical assessments, including econometric estimations, can be obtained from the authors on request. Owing to limits of space only the most important results will be presented. Some more descriptive analyses can be found in [21]).

Table 2 highlights respondents' preferences and viewpoint regarding vacations in Alpine environments including Alpine pastures. First of all, the most important reason for choosing Alpine regions and pastures for vacations is the (appealing) appearance of the Alpine landscape of which pastures are an essential element. As described in the introduction, tourism and destination marketing emphasize the landscape as one of the most important determinants of destination choice.

Other important motives of determining the destination of vacations include sports and recreation facilities, and reasonable prices.

Main sports activities of respondents during their vacations include swimming, hiking, cycling and mountaineering, all of which can be found in Austrian Alpine regions.

Most respondents stayed about one to two weeks per year in Alpine landscapes. The average length of stay was 10.23 days (standard deviation: 15.22 days; 2D group: 6.31 days; 3D group: 14.33 days). While this difference is somewhat striking, it seems that respondents who were randomly assigned to one of the (2D or 3D) groups indeed answered differently after watching the 2D or $3 \mathrm{D}$ presentation. As the groups are rather homogenous with respect to socioeconomic variables, the differences may indeed by caused by the mode of presentation; however, the differences are 
much less pronounced in the extended econometric model presented below in Section 4.2 which includes additional explanatory variables. Interestingly, the willingness-to-pay (WTP) to prevent one of the unsustainable scenarios of landscape changes was only slightly different between the groups (see below). Thus, there is no straightforward explanation in terms of distortions in the selection or random assignment of participants to the treatments; it seems, however, that respondents reacted differently between the groups in terms of travel behavior measured by the travel cost method, while economic values in terms of the sustainability of landscape changes (non-use values) are much less prone to a different perception and a different mode of presentation.

Table 2. Descriptive results: vacations and Alpine pastures.

\begin{tabular}{|c|c|}
\hline Variable Name & Results $^{1}$ \\
\hline $\begin{array}{l}\text { Main reason for choosing Alpine landscapes } \\
\text { with pastures as destinations of vacations }\end{array}$ & Percentage of respondents (multiple answers) \\
\hline Appearance of the landscape & $69.41 \%$ \\
\hline Reasonable prices & $47.06 \%$ \\
\hline Possibilities for sports & $44.71 \%$ \\
\hline Recreation possibilities & $42.35 \%$ \\
\hline Nature experience & $36.47 \%$ \\
\hline Comprehensive provision of hotels, restaurants & $18.82 \%$ \\
\hline Solitude & $12.94 \%$ \\
\hline Accessibility to the area & $10.59 \%$ \\
\hline Sightseeing & $9.41 \%$ \\
\hline Contact with wildlife & $5.88 \%$ \\
\hline Friendly to families and children & $3.53 \%$ \\
\hline Main sports activities & Percentage of respondents (multiple answers) \\
\hline Swimming & $65.88 \%$ \\
\hline Hiking & $51.76 \%$ \\
\hline Cycling & $37.65 \%$ \\
\hline Mountaineering & $20.00 \%$ \\
\hline Climbing & $14.12 \%$ \\
\hline Jogging & $9.41 \%$ \\
\hline Riding & $3.53 \%$ \\
\hline No sports & $2.35 \%$ \\
\hline Annual frequency and length of vacations in Alpine landscapes & Percentage of respondents \\
\hline More than 4 weeks & $14.29 \%$ \\
\hline Two to four weeks & $28.57 \%$ \\
\hline One to two weeks & $26.19 \%$ \\
\hline Less than one week & $21.43 \%$ \\
\hline No vacations in Alpine regions & $9.52 \%$ \\
\hline Importance and functions of Alpine pastures & Mean on a 4-point Likert scale $(4=$ most important $)$ \\
\hline Sustaining and support for biodiversity & 3.51 \\
\hline Preservation of cultural landscapes for recreation & 3.52 \\
\hline Ecological farming of classical pasture products & 3.46 \\
\hline Sustaining Alpine pasture as ancient culture & 3.17 \\
\hline Ecological, low-tech agriculture & 2.93 \\
\hline Keeping the landscape open & 2.38 \\
\hline
\end{tabular}

If scenario 1 ("afforestation") would become reality, respondents stated on average that they would reduce their length of stay to 4.52 days (std. dev. 11.34 days). However, respondents in the 2D group stated a reduced length of stay of 3.29 days, while respondents in the 3D group would reduce their stay to 5.78 days. If scenario 2 ("tourism") would be realized, the length of stay would on average be reduced to 4.17 days (2D group: 3.36 days; $3 \mathrm{D}$ group: 5.01 days). The stated reduction of the 3D group was thus much larger in relation to the stated length of stay before the scenarios would be realized.

Respondents also expressed their opinions concerning the functions of Alpine pastures; as the Table 2 shows, respondents clearly thought that the conservation of biodiversity typical for 
Alpine pastures, and the preservation of the landscape for recreation purposes were the most important functions.

Respondents were also asked to state their willingness-to-pay (WTP) for the prevention of either scenario 1 or scenario 2 . As the results in Table 3 suggest, WTP of respondents was-on average-about EUR 10.74 (for the total sample, scenario 1), and EUR 10.35 (for the total sample, scenario 2), respectively. The very small differences suggest that willingness-to-pay was not different between the two groups neither with respect to the scenarios nor the presentation (2D or 3D). These descriptive results are also corroborated by the econometric estimations (see Section 4.2), and suggest that differences in WTP to prevent landscape changes considered unfavorable are rather small between scenarios as well with respect to the mode of presentation (2D or 3D).

Table 3. Willingness-to-pay (WTP) to prevent scenario 1 or scenario 2.

\begin{tabular}{ccccccc}
\hline Variable & 2D Group & \multicolumn{2}{c}{ 3D Group } & \multicolumn{2}{c}{ Total Sample } \\
\hline & EUR (mean) & $n$ & EUR (mean) & $n$ & EUR (mean) & $n$ \\
WTP to prevent scenario 1 & 10.58 & 43 & 10.9 & 41 & 10.74 & 84 \\
WTP to prevent scenario 2 & 10.72 & 43 & 9.95 & 41 & 10.35 & 84 \\
\hline
\end{tabular}

Before turning to the econometric results with respect to travel frequency and WTP, Table 4 presents the results of the perception of respondents with respect to the group (2D vs. 3D). As the results indicate, there are only slight differences. While around $85 \%$ to $88 \%$ of respondents in both groups thought that 2D photos would present the landscape changes equally well, the 3D group stated that $3 \mathrm{D}$ presentations would be better to understand a problem of landscape change.

Table 4. Perception of 2D/3D presentations.

\begin{tabular}{|c|c|c|c|c|c|c|}
\hline Statements & \multicolumn{2}{|c|}{ 2D Group } & \multicolumn{2}{|c|}{ 3D Group } & \multicolumn{2}{|c|}{ Total Sample } \\
\hline $\begin{array}{l}\text { 3D presentations would have helped } \\
\text { to understand the topic and the } \\
\text { problems }\end{array}$ & $23 \%$ & 31 & & & & \\
\hline $\begin{array}{l}\text { Pictures present the issues and } \\
\text { problems equally well as the } 3 \mathrm{D} \\
\text { presentations }\end{array}$ & $85 \%$ & 39 & & & & \\
\hline $\begin{array}{l}\text { 3D presentations help to understand } \\
\text { the topic and the problems }\end{array}$ & & & $33 \%$ & 36 & & \\
\hline $\begin{array}{l}\text { Pictures would have presented the } \\
\text { issues and problems equally well as } \\
\text { the } 3 \mathrm{D} \text { presentations }\end{array}$ & & & $88 \%$ & 42 & & \\
\hline $\begin{array}{l}\text { 3D presentations contain } \\
\text { more information which } \\
\text { makes valuation more easy }\end{array}$ & 3.28 & 43 & 2.95 & 42 & 3.12 & 85 \\
\hline $\begin{array}{l}\text { 3D presentations are more modern and } \\
\text { correspond to modern technology }\end{array}$ & 3.44 & 43 & 3.79 & 42 & 3.61 & 85 \\
\hline
\end{tabular}

${ }^{1}$ Percentage of respondents agreeing to a statement/mean on a five-point Likert scale.

The other statements regarding 3D presentations were only slightly different between the two groups; a more pronounced, though not significant, difference occurred with the issue whether 3D presentation would contain more information. 


\subsection{Travel Frequency and Willingness-to-Pay for Preventing Unsustainable Landscape Changes}

The first econometric estimations presented in this paper consider modeling the frequency of visits based on the actual frequency, and the potential frequency of trips depending on the two scenarios. Based on the hypotheses discussed in Section 3.2, and the variables described in Table 1, the dependence of travel frequency of respondents is tested with a specific focus on the landscape change, and the presentation media in terms of $2 \mathrm{D}$ versus 3D. Table 5 presents the results of two estimations; the left side of the table includes details of the basic travel cost model by accounting solely for travel costs, the two scenarios, the 3D versus the 2D group, and income of respondents.

Table 5. Determinants of the respondents' travel frequency.

\begin{tabular}{|c|c|c|c|c|c|c|}
\hline \multirow[t]{2}{*}{ Variables $^{1}$} & \multicolumn{3}{|c|}{ Basic Travel Cost Model ${ }^{2}$} & \multicolumn{3}{|c|}{ Expanded Travel Cost Model $^{2}$} \\
\hline & Coeff. & $z$-Stat & Sign. ${ }^{3}$ & Coeff. & $z$-Stat & Sign. ${ }^{3}$ \\
\hline Constant & 0.1556 & 0.3273 & & 1.2389 & 2.171 & $* *$ \\
\hline Travelcost & -0.0023 & -3.2338 & $* * *$ & -0.0023 & -3.0682 & $* * *$ \\
\hline Scen1 & -0.9835 & -7.341 & $* * *$ & -0.9115 & -6.6756 & $* * *$ \\
\hline Scen 2 & -0.9541 & -7.157 & $* * *$ & -0.8858 & -6.5217 & $* * *$ \\
\hline Group & 0.3501 & 3.1551 & $* * *$ & 0.2165 & 1.8194 & $*$ \\
\hline Income1 & 0.3714 & 4.7842 & $* * *$ & 0.1973 & 2.2962 & $* *$ \\
\hline Essential & & & & 0.4518 & 3.0162 & $* * *$ \\
\hline Identity & & & & 0.5401 & 2.2008 & $* *$ \\
\hline Recreation & & & & -1.3437 & -4.8067 & $* * *$ \\
\hline Experience1 & & & & 0.5365 & 3.711 & $* * *$ \\
\hline Experience2 & & & & 0.3325 & 2.6367 & $* * *$ \\
\hline Adj. $R^{2}$ & & 0.1498 & & & 0.3065 & \\
\hline S.E. of regr. & & 7.8991 & & & 7.1341 & \\
\hline Log likelihood & & -560.7406 & & & -533.8609 & \\
\hline LR statistic & & $238.7263^{* * *}$ & & & $292.4857^{* * *}$ & \\
\hline$n$ & & 203 & & & 203 & \\
\hline
\end{tabular}

First of all, the estimations show that - in line with theoretical expectations - travel frequency depends significantly on travel costs (variable "Travelcost"). Given the negative coefficient of -0.0023 which is stable in both estimations, we may also compute consumer surplus per trip to an Alpine pasture (including the whole vacation during which the Alpine pasture was visited). Consumer surplus in our case amounts to a total of about 432 EUR per holiday trip; owing to the strong rejection of both scenarios 1 (reforestation, variable "Scen1") and 2 (intensive tourism, variable "Scen2"), respondents stated that they would change their travel frequency dramatically. As we discussed above, travel frequency might be significantly reduced from an average of 10.2 times in the last five years to about 4.5 times over the next five years. Considering all other variables—ceteris paribus-consumer surplus almost drops to one tenth of the original consumer surplus if the scenarios indeed are realized. This effect is only slightly smaller for the expanded travel cost model.

Furthermore, the group variable (variable "Group") differentiating the sample regarding their treatment with 3D versus the 2D version of the pictures presented in the survey interestingly leads to a significantly higher trip frequency. As described above in Section 4.1, the respondents in the 3D treatment stated a trip frequency of about 14 over the last five years, while respondents in the $2 \mathrm{D}$ treatment only said that they would have visited Alpine pasture about 6.5 times. This significant difference is also indicated by the significant coefficient of 0.3501 in the basic travel cost model (left side of Table 5), which leads to a welfare effect in terms of an additional consumer surplus of EUR 152 per vacation. However, the effect is again much smaller in the estimation of the expanded travel cost model; for this case, the additional consumer surplus attributable to the $3 \mathrm{D}$ version of the presentation amounts to EUR 95 per vacation. As mentioned before, there are no straightforward explanations for 
these significant differences other than the randomly chosen affiliation of participants to the 3D group in contrast to the $2 \mathrm{D}$ group.

Finally, the variable "Income1" was also included in the basic estimation to ascertain the importance of socioeconomic variables. The estimation of both the basic and the expanded travel cost model suggest that-congruent with the theoretical expectations-travel frequency of respondents increases with income. The difference of travel frequency between the two groups becomes smaller when more explanatory variables are added to the model (see right part of Table 5 with a smaller and less significant coefficient for the variable "Group").

In order to ascertain additional determinants of travel frequency, and to control for potential influences of the perception of Alpine pastures, Table 5 also shows the results of the expanded travel cost model. In this expanded model, more variables are included that may be closely connected to respondents' preferences for vacations in Alpine environments. The estimation reveals that respondents who stated that Alpine pastures would be essential for the appearance of the landscape indicate a higher travel frequency (variable "Essential"). Furthermore, the variables "Identity" (denoting respondents who thought that Alpine pastures would contribute to the national identity), "Experience1" (for respondents having experienced reforestation of Alpine pastures) and "Experience2" (for respondents having experienced intensive tourism on pastures) state stronger preferences for the Alpine pasture presented in the experiment. Otherwise, respondents who stated that recreation would be an important ecosystem service of Alpine pastures (variable "Recreation") exhibit a below-average frequency of trips to such areas.

All in all, the travel frequency model, while it is—of course-not representative for the Austrian population, exhibits interesting results in terms of the popularity of landscape changes, and the importance of presentation media. There seems to be a strong preference of respondents for the appearance of Alpine pastures corresponding to the usual "image" communicated by the tourism offices all over the Alps. In addition, it seems that travel frequency stated by respondents is influenced by the presentation media in the sense that $3 \mathrm{D}$ presentations motivate respondents to state higher trip frequencies than in the 2D treatment.

In order to explore the influence of 3D versus 2D presentations, Table 6 presents the results of a maximum likelihood estimation of the determinants of the respondent's willingness-to-pay for the prevention one of the two scenarios. The table again shows two estimations, one with essentially three variables (variable "Scen2" with the willingness-to-pay to prevent scenario 1 as the baseline), the variable "Group" and the variable "Income2". Regarding the variable "Income2", we used a different income variable for the estimation of willingness-to-pay; since the sample for this estimation is smaller than for the estimation of travel frequency in Table 5, we had to use a simpler income variable with only two income classes (instead of the continuous income variable). The simple estimation on the left-hand side of Table 6 only provides some indication that-as theory predicts—the respondent's willingness-to-pay is positively correlated with income. However, at first sight, there does not seem to be much difference with respect to the scenario for which a willingness-to-pay to prevent was elicited, and to the presentation media (3D versus $2 \mathrm{D}$ ).

However, the right-hand side of Table 6 includes some additional variables that have already been used for explaining trip frequency. Enriching the picture with these variables leads to interesting results regarding the determinants of willingness-to-pay of participants in the experiment. While the coefficients and their significance of variables "Income2" and "Scen2" basically remain unchanged, the variable 'Group' is now weakly significant with small coefficient of -0.1224 . This means that respondents in the 3D group in general stated a slightly smaller willingness-to-pay (on average, willingness-to-pay is about $10 \%$ lower in the 3D group than in the 2D group).

In addition to the explanatory variables already mentioned, it seems that preferences determine willingness-to-pay to a much higher degree that the way of presenting potential landscape changes. As expected, willingness-to-pay of respondents_ceteris paribus-increases with the acceptance of 
statements regarding the importance of Alpine pastures for the landscape, for recreation, and with respect to the personal experiences of respondents.

Table 6. Determinants of the respondents' WTP to prevent landscape changes considered to be unsustainable.

\begin{tabular}{ccccccc}
\hline Variables $^{1}$ & \multicolumn{3}{c}{ Basic WTP Model $^{2}$} & \multicolumn{3}{c}{ Expanded WTP Model $^{2}$} \\
\hline & Coeff. & $z$-Stat & Sign. ${ }^{3}$ & Coeff. & $z$-Stat & Sign. $^{3}$ \\
Constant & 2.2721 & 48.7988 & $* * *$ & 1.9323 & 9.0088 & $* * *$ \\
Scen2 & -0.0511 & -1.0442 & & -0.0509 & -1.0225 & \\
Group & -0.0246 & -0.5027 & & -0.1224 & -2.3613 & $* *$ \\
Income2 & 0.2805 & 5.6222 & $* * *$ & 0.2865 & 5.3073 & $* * *$ \\
Essential & & & 0.1096 & 1.7697 & $*$ \\
Identity & & & -0.2330 & -2.7955 & $* * *$ \\
Recreation & & & 0.5851 & 2.9496 & $* * *$ \\
Experience1 & & & 0.4570 & 8.0454 & $* * *$ \\
Experience2 & & & -0.3519 & -6.8151 & $* * *$ \\
Quasi-log & & & & 2401.6600 & \\
likelihood. & 2309.2520 & & $218.1369^{* * *}$ & \\
LR stat. & $33.3217^{* * *}$ & & 18.3237 & \\
Deviance stat. & 18.9026 & & & 165 & \\
n & 165 & & & & \\
\hline
\end{tabular}

${ }^{1}$ Dependent variable: WTP (baseline is the WTP for preventing scenario 1); ${ }^{2}$ GLM (maximum likelihood) estimation (Poisson distribution assumed, $\log \operatorname{link}$ ); ${ }^{* * *} p<0.01,{ }^{* *} p<0.05,{ }^{*} p<0.1$

\section{Discussion, summary, and conclusions}

Based on a picture of an Alpine pasture in the Austrian Alps, used as status quo for the rest of the (non-representative) spatial simulation experiment and survey, two hypothetical scenarios of landscape transformations were developed. These ought to illustrate potential qualitative changes of the current appearance of the landscape with respect to values associated with the natural and cultural heritage of Alpine pastures.

While in the first scenario, reforestation takes place, either naturally or artificially and as a consequence of the closing of farms in the Alpine zones, the second scenario assumes an infrastructure expansion due to the increase of tourism. These scenarios were created and visualized through (digital) manipulation of the status quo picture.

Travel frequency, distance, and traveling time were used as indicators to determine the travel costs of the respondents, and combined with an estimation computing recreation benefits (consumer surplus). Furthermore, the interviewees (in a class room experiment) were asked to state their estimated future visit frequency to the two modified scenarios within the next five years, as well as their willingness to pay (WTP) in order to avoid each scenario, i.e., prevent landscape changes considered to be undesirable.

A second aspect of this study focuses on the presentation of the landscape scenery and their transformations. In addition to the already mentioned status quo picture and the two scenario photographs (2D), stereoscopic 3D-pictures of the various scenarios were produced as well. The aim of this experiment was therefore to identify the effects of these different presentations on the results. The survey participants were randomly divided into two groups in a classroom experiment, one evaluating the landscape scenery using questionnaires with photographs (2D), and the other using an almost similar questionnaire with stereoscopic 3D-pictures, which were presented in the Department of Spatial Planning's spatial simulation laboratory.

Respondents of the 3D group state a significantly higher trip frequency than the 2D group; they also reacted to the 3D presentation of landscape changes differently, in the sense that they were more sensitive to disadvantageous transformations of the appearance of the Alpine pastures. 
The results show that the landscape scenery status quo was clearly preferred. Additionally, the modified scenarios have a significant negative impact on trip frequency. Furthermore, the consumer surplus drops enormously when the landscape scenery changes.

Concerning the different forms of representation (2D vs. 3D), significant differences between the two samples were found. This means that the different presentation methods of the hypothetical situations had a significant impact on trip frequency and, to a much smaller extent, on the willingness to pay in the (non-representative) experimental setting. While the 3D group stated a higher trip frequency compared to the 2D group - controlled for potential differences, e.g., regarding income, willingness-to-pay was marginally higher in the $2 \mathrm{D}$ group compared to the $3 \mathrm{D}$ group. As the sample of respondents was restricted to undergraduate students, the results in terms of absolute numbers of trips or the size of WTP are not representative for the general population. However, it is reasonable to assume that differences in perception are qualitatively equal between the participants of the experiment and the general population, i.e., that differences go in the same direction.

Interestingly, when asked for their evaluation of 3D versus 2D, the 3D group underestimated the influence of the presentation form as they did not expect additional information or a different perspective of the landscape. The $2 \mathrm{D}$ group had somewhat different expectations about $3 \mathrm{D}$ presentations in the sense that they expected an improved spatial perception of $3 \mathrm{D}$ versus 2D presentations.

All in all, the study thus provides experimental evidence that the mode of presentation (2D vs. 3D) may alter the respondents' economic valuation of landscape changes by a different spatial perception of landscape changes depending on the economic valuation approach (travel frequency versus elicitation of WTP to prevent landscape changes considered unfavorable). However, it has to be tested in additional (representative) experiments in which reasoning may be developed for these effects, and whether the results of this study are robust and can be reproduced in different settings. Regarding the valuation of changes to the natural and cultural heritage-in this case, a traditional Alpine landscape- the results of this study thus indicate that for presenting and visualizing the consequences of different management regimes, researchers and planners have to bear in mind that not only traditional forms of surveys may be used, but that the form of presentation might alter the results. Therefore, policies that promote sustainable management of Alpine pastures as part of national heritage are strongly advised to fruitfully make use of the wide range of valuation techniques and results in order to enrich decision making processes, not only with bare economic figures but also to account for the substantial inputs of different perceptions and perspectives on landscape changes.

Acknowledgments: We thank the participants of the European Society of Ecological Economics (ESEE) conference (30 June to 3 July 2015, Leeds, UK) for their comments. Anonymous reviewers provided many helpful suggestions for substantial improvements of the paper. All errors are, of course, the responsibility of the authors.

Author Contributions: All authors equally conceived and designed the experiment, and performed the experiment; Barbara Färber and Michael Getzner analyzed the data; Michael Getzner and Claudia Yamu wrote the main parts of the paper.

Conflicts of Interest: The authors declare no conflict of interest.

\section{References}

1. Zoderer, B.M.; Tasser, E.; Erb, K.-H.; Lupo Stanghellini, P.S.; Tappeiner, U. Identifying and mapping the tourists' perception of cultural ecosystem services: A case study from an Alpine region. Land Use Policy 2016, 56, 251-261. [CrossRef]

2. Bednar-Friedl, B.; Behrens, D.; Getzner, M. Socioeconomics of conservation in the Alps. In The Alpine Environment: Geology, Ecology and Conservation; Schmidt, J.G., Ed.; NOVA Science Publishers: Hauppauge, NY, USA, 2011; pp. 135-152.

3. Vos, W.; Meekes, H. Trends in European cultural landscape development: Perspectives for a sustainable future. Landsc. Urban Plan. 1999, 46, 3-14. [CrossRef] 
4. Plieninger, T.; Höchtl, F.; Spek, T. Traditional land-use and nature conservation in European rural landscapes. Environ. Sci. policy 2006, 9, 317-321. [CrossRef]

5. Lienhoop, N.; Ansmann, T. Valuing water level changes in reservoirs using two stated preference approaches: An exploration of validity. Ecol. Econ. 2011, 70, 1250-1258. [CrossRef]

6. Getzner, M.; Svajda, J. Preferences of tourists with regard to changes in the landscape of the Tatra National Park in Slovakia. Land Use Policy 2015, 48, 107-119. [CrossRef]

7. Whitehead, J.C.; Haab, T.C.; Huang, J.-C. Measuring recreation benefits of quality improvements with revealed and stated behavior data. Resour. Energy Econ. 2000, 27, 339-354. [CrossRef]

8. Hoyos, D.; Riera, P. Convergent validity between revealed and stated recreation demand data: Some empirical evidence from the Basque Country, Spain. J. For. Econ. 2013, 19, 234-248. [CrossRef]

9. Zech, S. Raum planen ohne Pläne? In Jahrbuch Raumplanung 2013; Bröthaler, J., Getzner, M., Giffinger, R., Hamedinger, A., Voigt, A., Eds.; NWV Verlag: Vienna, Austria, 2013; pp. 69-86.

10. Tisma, A.; Knegt, B.; Van Egmond, P. Evaluation of visualization techniques in communicating nature perspectives. In Proceedings of the AESOP-ACSP Joint Congress, Conference Paper, Dublin, Ireland, 15-19 July 2013.

11. Pietsch, S. Computer visualization in the design and control of urban environments: A literature review. Environ. Plan. B 2000, 27, 521-536. [CrossRef]

12. Roupé, M.; Johansson, M. Supporting 3D City Modelling, Collaboration and Maintenance through an Open-Source Revision Contol System. In New Frontiers, Proceedings of the 15th International Conference on Computer-Aided Architectural Design Research in Asia CAADRIA, Hongkong, China, 14-17 May 2010; Dave, B., Li, A., Park, H.-J., Eds.; pp. 347-356. Available online: http:/ /www.caadria.org/cnf/index.html (accessed on 21 June 2016).

13. Fiore, S.M.; Harrison, G.W.; Hughes, C.E. Virtual experiments and environmental policy. J. Environ. Manag. 2009, 57, 65-86. [CrossRef]

14. Schroth, O.; Pond, E.; Sheppard, S.R.J. Evaluating presentation formats of local climate change in community planning with regard to process and outcomes. Landsc. Urban Plan. 2015, 142, 147-158. [CrossRef]

15. Grêt-Regamey, A.; Celio, E.; Klein, T.M.; Wissen Hayek, W. Understanding ecosystem services trade-offs with interactive procedural modeling for sustainable urban planning. Landsc. Urban Plan. 2013, 109, 107-116. [CrossRef]

16. Thill, J.-C.; Dao, T.H.D.; Zhou, Y. Traveling in the three-dimensional city: Applications in route planning, accessibility assessment, location analysis and beyond. J. Transp. Geogr. 2011, 19, 405-421. [CrossRef]

17. Bishop, I.D.; Stock, C. Using collaborative virtual environments to plan wind energy installations. Renew. Energy 2010, 35, 2348-2355. [CrossRef]

18. Benoit, A.; Le Callet, P.; Campisi, P.; Cousseau, R. Quality assessment of stereoscopic images. EURASIP J. Image Video Process. 2008. [CrossRef]

19. Tauer, H. Stereo 3D. Grundlagen, Technik und Bildgestaltung; Fachverlag Schiele und Schön: Berlin, Germany, 2010. (In German)

20. Liebold, B.; Pietschmann, D.; Valtin, G.; Ohler, P. Taking Space Literally: Reconceptualizing the Effects of Stereoscopic Representation on User Experience. 2013. Available online: http:/ /www.gamejournal.it/takingspace-literally-reconceptualizing-the-effects-of-stereoscopic-representation-on-user-experience/ (accessed on 21 June 2016).

21. Färber, B. Die ökonomische Bewertung der Veränderung des Landschaftsbildes Alm. Master's Thesis, Department of Spatial Planning, Vienna University of Technology, Vienna, Austria, November 2014.

22. Antonides, G.; Bolger, F.; Trip, G. Classroom experiments in behavioral economics. In Handbook of Contemporary Behavioral Economics: Foundations and Developments; Altman, M., Ed.; M.E. Sharpe: New York, NY, USA, 2006; pp. 379-404.

23. Centre for Spatial Simulation and Modelling. Information and technical details about the spatial simulation laboratory at the Department of Spatial Planning at the Vienna University of Technology. 2016. Available online: simlab.tuwien.ac.at (accessed on 20 June 2016).

24. Bergstrom, J.C.; Stoll, J.R.; Randall, A. The impact of information on environmental commodity valuation decisions. Am. J. Agric. Econ. 1990, 72, 614-621. [CrossRef]

25. Getzner, M. The regional context of infrastructure policy and environmental valuation: The importance of stakeholders' opinions. J. Environ. Econ. Policy 2012, 1, 255-275. [CrossRef] 
26. Ajzen, I.; Brown, T.C.; Rosenthal, L.H. Information bias in contingent valuation: Effects of personal relevance, quality of information, and motivational orientation. J. Environ. Econ. Manag. 1996, 30, 43-57. [CrossRef]

27. Bartkowski, B.; Lienhoop, N.; Hansjürgens, B. Capturing the complexity of biodiversity: A critical review of economic valuation studies of biological diversity. Ecol. Econ. 2015, 113, 1-14. [CrossRef]

28. Phaneuf, D.J.; Smith, V.K. Recreation demand models. In Handbook of Environmental Economics; Mäler, K.G., Vincent, J., Eds.; Elsevier: North Holland, Amsterdam, The Netherlands, 2005; Volume 2, pp. 671-761.

29. Randall, A. A difficulty with the travel cost method. Land Econ. 1994, 70, 88-96. [CrossRef]

(C) 2016 by the authors; licensee MDPI, Basel, Switzerland. This article is an open access article distributed under the terms and conditions of the Creative Commons Attribution (CC-BY) license (http://creativecommons.org/licenses/by/4.0/). 